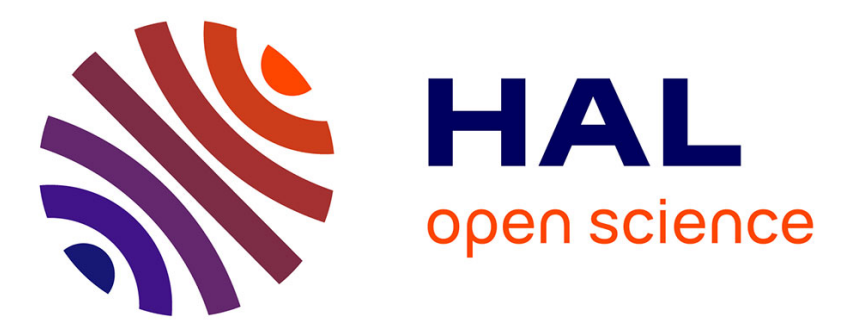

\title{
TOWARDS 3-D TISSUE DOPPLER ULTRAFAST ECHOCARDIOGRAPHY: AN IN VITRO STUDY
}

Emilia Badescu, Lorena Petrusca, Damien Garcia, Denis Friboulet, Hervé Liebgott

\section{- To cite this version:}

Emilia Badescu, Lorena Petrusca, Damien Garcia, Denis Friboulet, Hervé Liebgott. TOWARDS 3-D TISSUE DOPPLER ULTRAFAST ECHOCARDIOGRAPHY: AN IN VITRO STUDY. 2017 IEEE International Ultrasonic Symposium (IUS), Sep 2017, Washington, United States. hal-01598539

\section{HAL Id: hal-01598539 \\ https://hal.science/hal-01598539}

Submitted on 25 Mar 2019

HAL is a multi-disciplinary open access archive for the deposit and dissemination of scientific research documents, whether they are published or not. The documents may come from teaching and research institutions in France or abroad, or from public or private research centers.
L'archive ouverte pluridisciplinaire HAL, est destinée au dépôt et à la diffusion de documents scientifiques de niveau recherche, publiés ou non, émanant des établissements d'enseignement et de recherche français ou étrangers, des laboratoires publics ou privés. 


\title{
TOWARDS 3-D TISSUE DOPPLER ULTRAFAST ECHOCARDIOGRAPHY: AN IN VITRO STUDY
}

\author{
Emilia Badescu, Lorena Petrusca, Damien Garcia, Denis Friboulet, Hervé Liebgott \\ Univ Lyon, INSA-Lyon, Université Claude Bernard Lyon 1, UJM-Saint Etienne, CNRS, Inserm, CREATIS UMR 5220, U1206, \\ F-69100, LYON, France \\ Email: emilia.badescu@creatis.insa-lyon.fr
}

\begin{abstract}
The emergence of ultrafast imaging allows new insights into cardiac deformation/motion analysis that could enable new advancements in clinical diagnosis. Several studies showed that a good compromise between the temporal and the spatial resolution can be obtained by transmitting multiple focused beams simultaneously, method referred in literature as MLT (multi line transmit). However, previous investigations on 3D MLT were limited to simulations or retrospective synthetic implementations, and thus cannot be used in dynamic conditions. The objective of this study was to evaluate the performance of MLT on a moving phantom represented by a spinning disk. Images of the in vitro model were acquired using four Verasonics systems synchronized to drive a $32 \times 32$ Vermon probe. The Doppler velocities were estimated on volumetric data using an ensemble auto-correlator. The results showed that the images acquired using MLT can provide accurate Doppler velocities (mean relative error in the entire volume $=4.1 \%$ ). MLT allowed an 8-fold increase in volume rate with preserved Doppler image quality, which could open up new clinical opportunities in cardiac echo imaging.
\end{abstract}

Keywords-ultrasound, high frame rate, multi-line transmit, $3 D$ imaging, experimental validation

\section{INTRODUCTION}

Two-dimensional (2D) echocardiography is the modality of choice in current clinical practice due to its wide accessibility, noninvasive nature, low cost and high potential in clinical diagnosis. Clinicians now agree that 3D echocardiography can be complementary to 2D echocardiography. This imaging modality, however, is still rarely used at patient bedside since it is not possible to perform volumetric sequences at adequate temporal and spatial resolutions in a single heart-beat. The alternative multi-plane 2D imaging for reconstructing volumetric measurements and motion may lead to unreliable physiological parameters due to missing out-ofplane components.

Achieving high-frame-rate 3D echocardiography is highly relevant for clinical diagnosis. For example, improving temporal resolution of 3D echo would allow capturing rapid phases of the whole left ventricle for a better assessment of cardiac function. Furthermore, pediatric echocardiography [1], blood flow quantification [2], assessment of the electromechanical properties [3] could also benefit from 3D ultrafast echocardiography.

Conventional methods such as sector angle reduction, decrease in line density, multi-line-acquisition (MLA) [4], [5] and retrospective electrocardiogram gating [6] have been already extended to 3D imaging. Other approaches based on plane/diverging waves were also introduced to further increase frame rates [7]-[9]. However, the main disadvantage of the wide-beam methods is the trade off with image quality. An alternative technique to reach high frame rates with a minimum impact on spatial resolution is multi-line transmit (MLT). Several studies demonstrated the potential of this method in 2D [10], [11]. Even if MLT may lead to cross-talk artefacts, it has been proved to be very competitive with the conventional single-line transmission, especially if the beams are properly positioned [12], if an adequate apodization is used [13] or if minimum variance beamforming is employed [14]. However, the previous 3D MLT investigations were limited to simulations and could not be used in dynamic conditions due to their retrospective synthetic implementations. More specifically, the channel data corresponding to different SLT (single line transmit) sequences were synthetically summed before beamforming [15].

In this work, we present a feasibility study of 3D MLT on an in vitro phantom of a rotating disk. The MLT real-time acquisitions were then used to compute the Doppler velocities to investigate the potential of the method for tissue Doppler applications.

\section{METHODS}

\section{A. In vitro model}

Our in vitro model was a tissue mimicking spinning disc with a diameter of $10 \mathrm{~cm}$ whose speed could be controlled by a step motor. The disk was placed at $1.6 \mathrm{~cm}$ away from the transducer and the image depth was $\sim 10.5 \mathrm{~cm}$. The experimental set-up is illustrated in Figure 1. 


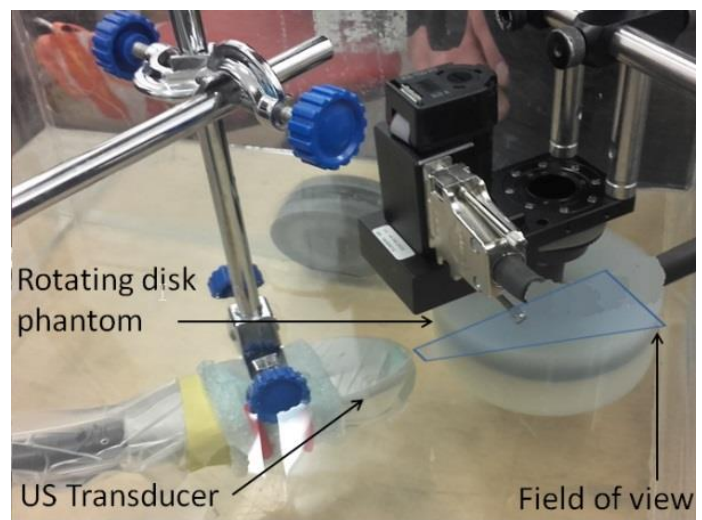

Figure 1: Experimental set-up

The phantom was rotated at an angular velocity of 200 degrees $/ \mathrm{s}$. This set-up gave a maximum velocity of $17.4 \mathrm{~cm} / \mathrm{s}$, which corresponds to myocardial peak velocities reported in [16]. The PRF was set to $2250 \mathrm{~Hz}$ (Nyquist velocity $=29$ $\mathrm{cm} / \mathrm{s})$.

\section{B. In vitro acquisitions}

The 3D images were acquired by using four Verasonics research scanners, each of them controlling $8 \times 32$ elements of a $32 \times 32,3-\mathrm{MHz}$ Vermon ultrasound transducer [17]. The RF signals were sampled at four times the central frequency (12 $\mathrm{MHz}$ ). A scan volume was created by stitching 32 triangular sectors (each of angular width $=60^{\circ}$ ) along the azimuthal direction. For each triangular sector, 4 transmission events were used to insonify a full sector by sending simultaneously 8 equidistant focused MLT beams. The total number of transmissions was thus 128 , corresponding to 32 (elevational) $\times 32$ (azimuthal) focal beams. The transmission scheme is represented in Figure 2:

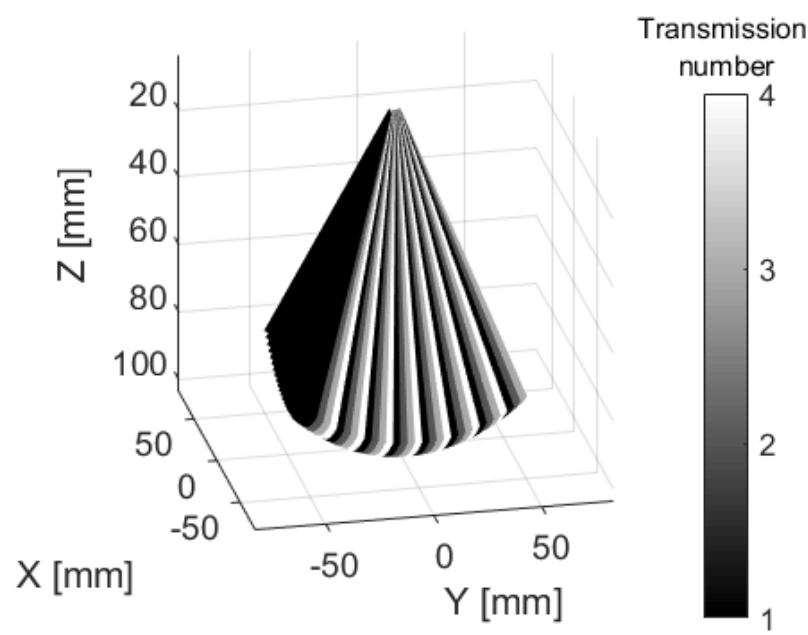

Figure 2. Transmission scheme: Four transmissions of 8 MLT beams are used to insonify an entire sector. For a full volume, the process is repeated 32 times
The focal points were located at $6.7 \mathrm{~cm}$ from the transducer and no apodization was used either in emission or reception. The beamformed RF data were IQ-demodulated offline. In-plane axial Doppler velocities were then estimated using a $2 \mathrm{D}$ auto-correlator and a packet length of 7 [18].

\section{RESULTS}

The multi-plane Doppler velocity volume is presented in Figure 3. The estimated velocity values (B) were in agreement with the expected velocities (A). The mean relative error was $4.1 \%$. Additionally, we obtained an eight-fold increase in volume rate compared with $\mathrm{Tx}$-focused imaging.
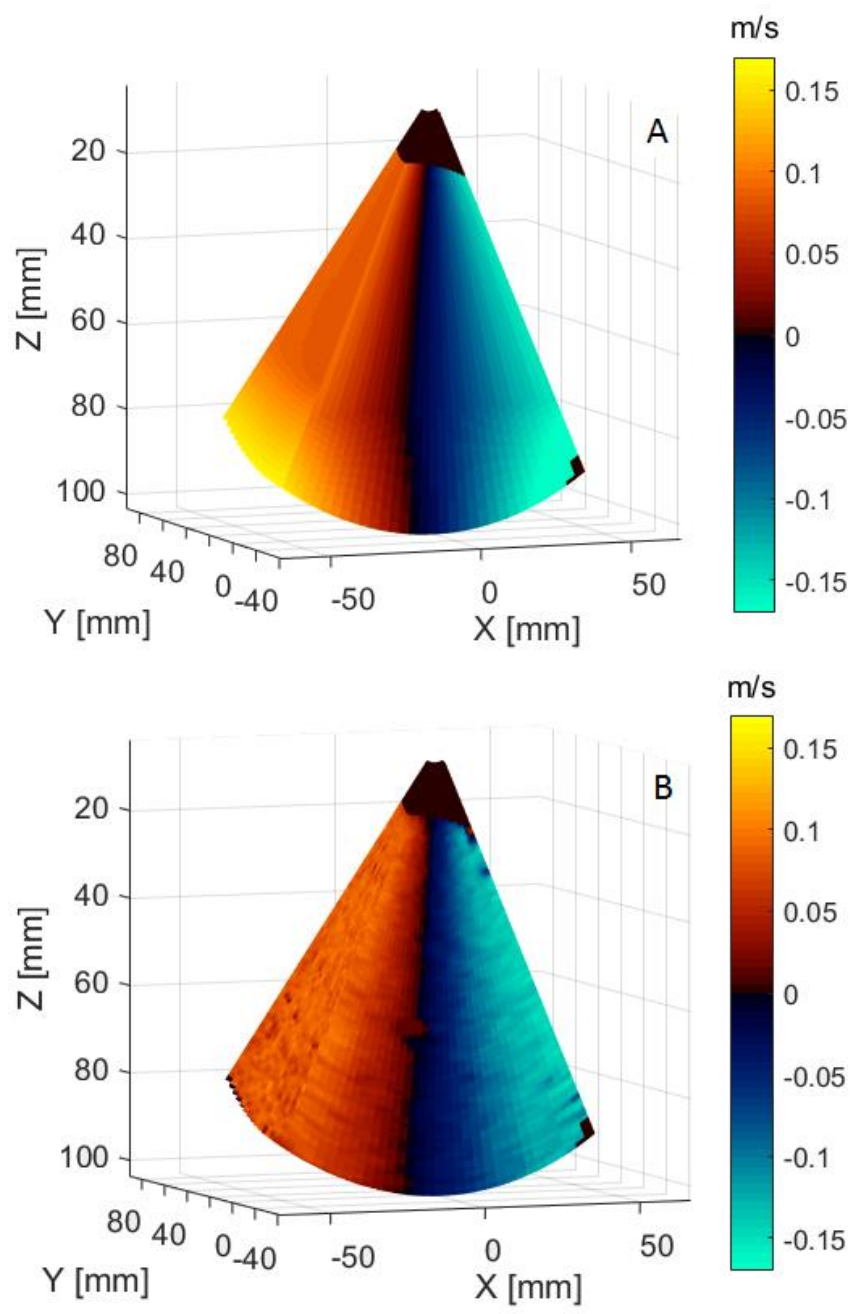

Figure 3. Multiple plane velocity map: A. Reference velocity map; B. Estimated velocity map 


\section{DISCUSSION AND CONCLUSION}

This study demonstrates the feasibility of tissue Doppler velocity estimation for 3D MLT ultrasound imaging. The results showed that accurate estimators can be obtained even if no apodization was used either in emission or in reception. Analyzing further different MLT configurations would allow obtaining the optimal compromise between high volume rate and quality color Doppler.

In this work the volume rate was increased 8 times while the image quality was preserved to allow accurate velocity estimators. Using 3D MLT could allow new advancements in ultrafast color Doppler. The extension of the velocity estimator in $3 \mathrm{D}$ would enable a complete quantification of the heart velocities.

\section{ACKNOWLEDGMENT}

This project has received funding from the European Union's Horizon 2020 research and innovation programme under the Marie Skłodowska-Curie grant agreement No 642612, VPH-CaSE (www.vph-case.eu). This work was performed within the framework of the LABEX PRIMES (ANR-11-LABX-0063) of Université de Lyon, within the program "Investissements d'Avenir" (ANR-11-IDEX-0007) operated by the French National Research Agency (ANR).

The authors would like to thank LabTAU for their contribution in the development of the $32 \times 32$ probe prototype compatible with a driving by 1 to 4 Verasonics Vantage 256 as well as for the provision of the probe and two Vantage 256 systems. Two Verasonics systems were acquired thanks to the program FEDER Saint-Etienne and Loire General Council in the framework of the project SonoCardioProtection supervised by Pierre Croisille.

\section{REFERENCES}

[1] S. Fadnes, M. Wigen, S. A. Nyrnes, and L. Lovstakken, "In vivo intracardiac vector velocity imaging using phased array transducers for pediatric cardiology," IEEE Trans. Ultrason. Ferroelectr. Freq. Control, pp. 1-1, Apr. 2017.

[2] J. Faurie, M. Baudet, K. C. Assi, D. Auger, G. Gilbert, F. Tournoux, and D. Garcia, "Intracardiac Vortex Dynamics by High-Frame-Rate Doppler Vortography-In Vivo Comparison With Vector Flow Mapping and 4-D Flow MRI," IEEE Trans. Ultrason. Ferroelectr. Freq. Control, vol. 64, no. 2, pp. 424-432, Feb. 2017.

[3] J. Provost, Wei-Ning Lee, K. Fujikura, and E. E. Konofagou, "Electromechanical Wave Imaging of Normal and Ischemic Hearts In Vivo," IEEE Trans. Med. Imaging, vol. 29, no. 3, pp. 625-635, Mar. 2010.

[4] D. P. Shattuck, M. D. Weinshenker, S. W. Smith, and O. T. von Ramm, "Explososcan: A parallel processing technique for high speed ultrasound imaging with linear phased arrays," J. Acoust. Soc. Am., vol. 75, no. 4, pp. 1273-1282, Apr. 1984.

[5] O. T. von Ramm, S. W. Smith, and H. G. Pavy, "High-speed ultrasound volumetric imaging system. II. Parallel processing and image display," IEEE Trans. Ultrason. Ferroelectr. Freq. Control, vol. 38, no. 2, pp. 109-115, Mar. 1991.

[6] S. Shougang Wang, W.-N. Wei-ning Lee, J. Provost, J. Jianwen Luo, and E. E. Konofagou, "A composite highframe-rate system for clinical cardiovascular imaging," IEEE Trans. Ultrason. Ferroelectr. Freq. Control, vol. 55, no. 10, pp. 2221-2233, Oct. 2008.

[7] L. Tong, H. Gao, H. Choi, and J. D'hooge, "Comparison of conventional parallel beamforming with plane wave and diverging wave imaging for cardiac applications: a simulation study," IEEE Trans. Ultrason. Ferroelectr. Freq. Control, vol. 59, no. 8, pp. 1654-1663, Aug. 2012.

[8] H. Hasegawa and H. Kanai, "High-frame-rate echocardiography using diverging transmit beams and parallel receive beamforming."

[9] C. Papadacci, M. Pernot, M. Couade, M. Fink, and M. Tanter, "High-contrast ultrafast imaging of the heart," IEEE Trans. Ultrason. Ferroelectr. Freq. Control, vol. 61, no. 2, pp. 288-301, Feb. 2014.

[10] R. Mallart and M. Fink, "Improved imaging rate through simultaneous transmission of several ultrasound beams," 1992, pp. 120-130.

[11] L. Tong, A. Ramalli, R. Jasaityte, P. Tortoli, and J. D'hooge, "Multi-Transmit Beam Forming for Fast Cardiac Imaging - Experimental Validation and In Vivo Application," IEEE Trans. Med. Imaging, vol. 33, no. 6, pp. 1205-1219, Jun. 2014.

[12] B. Denarie, T. Bjastad, and H. Torp, "Multi-line transmission in 3-D with reduced crosstalk artifacts: a proof of concept study," IEEE Trans. Ultrason. Ferroelectr. Freq. Control, vol. 60, no. 8, pp. 1708-1718, Aug. 2013.

[13] L. Tong, H. Gao, and J. D'hooge, "Multi-transmit beam forming for fast cardiac imaging-a simulation study," IEEE Trans. Ultrason. Ferroelectr. Freq. Control, vol. 60, no. 8, pp. 1719-1731, Aug. 2013.

[14] A. Rabinovich, A. Feuer, and Z. Friedman, "Multi-line transmission combined with minimum variance beamforming in medical ultrasound imaging," IEEE Trans. Ultrason. Ferroelectr. Freq. Control, vol. 62, no. 5, pp. 814-827, May 2015.

[15] A. Ortega, J. Provost, L. Tong, P. Santos, B. Heyde, M. Pernot, and J. D'hooge, "A Comparison of the Performance of Different Multiline Transmit Setups for Fast Volumetric Cardiac Ultrasound," IEEE Trans. Ultrason. Ferroelectr. Freq. Control, vol. 63, no. 12, pp. 2082-2091, Dec. 2016.

[16] S. F. Nagueh, K. J. Middleton, H. A. Kopelen, W. A. Zoghbi, and M. A. Quiñones, "Doppler Tissue Imaging: A Noninvasive Technique for Evaluation of Left Ventricular Relaxation and Estimation of Filling Pressures," J. Am. Coll. Cardiol., vol. 30, no. 6, pp. 1527-1533, Nov. 1997.

[17] M. . Petrusca, L.; Varray, F.; Souchon, R.; Bernard, A.; Chapelon, J.Y.; Liebgott, H.; N'Djin, W.A.; Viallon, "A 
new high channels density ultrasound platform for advanced 4D cardiac imaging," in IEEE Internation Ultrasonics Symposium, 2017.

[18] T. Loupas, J. T. Powers, and R. W. Gill, "An axial velocity estimator for ultrasound blood flow imaging, based on a full evaluation of the Doppler equation by means of a twodimensional autocorrelation approach," IEEE Trans. Ultrason. Ferroelectr. Freq. Control, vol. 42, no. 4, pp. 672-688, Jul. 1995.

[19] J. Poree, D. Posada, A. Hodzic, F. Tournoux, G. Cloutier, and D. Garcia, "High-Frame-Rate Echocardiography Using Coherent Compounding With Doppler-Based MotionCompensation," IEEE Trans. Med. Imaging, vol. 35, no. 7, pp. 1647-1657, Jul. 2016. 